\title{
ANÁLISE ACÚSTICA \\ E MODELO REPRESENTACIONAL: \\ UMA PROPOSTA INICIAL \\ DE ENTENDIMENTO DOS \\ DESVIOS FONOLÓGICOS
}

ANÁLISIS ACÚSTICA Y MODELO REPRESENTACIONAL:

UNA PROPUESTA INICIAL DE ENTENDIMIENTO DE LOS TRASTORNOS FONOLÓGICOS

ACOUSTIC ANALYSIS AND REPRESENTATIONAL MODEL:

AN INITIAL PROPOSAL FOR UNDERSTANDING PHONOLOGICAL DISORDERS

Carla Cristofolini*

Prefeitura Municipal de São José

Cristiane Lazzarotto-Volcão**

Universidade Federal de Santa Catarina

*Fonoaudióloga, Mestre e Doutora em Linguística (UFSC), fonoaudióloga educacional da Secretaria Municipal de

EducaçãodeSãoJosé/SC.migola@uol.com.br.

** Mestre e Doutora em Letras (UCPel), com pós-doutorado no Centro de Linguística da Universidade de Lisboa Professora Associada da UFSC, onde atua no curso de Graduação em Letras Português e no Programa de Pós-Graduação em Linguística.cristiane.volcao@gmail.com. 
RESUMO: Este artigo trata de um estudo de caso, em que é realizada uma análise dos dados de fala de uma criança de 5 anos de idade, com desvio fonológico, com o objetivo de aliar uma análise fonológica, mediada por um modelo representacional de base gerativa, a uma perspectiva objetiva, por meio da análise acústica. Em especial, discute-se acerca dessa possibilidade, a partir do estudo da produção da classe das fricativas, buscando, também, o aprofundamento da avaliação fonético-fonológica, enriquecendo a análise do sistema fonológico atípico da criança. Ao final, é feita uma discussão das vantagens de uma abordagem desse tipo para a terapia fonoaudiológica, bem como uma discussão em torno da viabilidade de uma análise dessa natureza.

PALAVRAS-CHAVE: Análise acústica. Desvio fonológico. Fricativas.

RESUMEN: Este artículo hace un análisis de los datos de habla de un niño de 5 años de edad, con trastorno fonológico, con el objetivo de aliar un análisis fonológico, mediado por un modelo representativo de base generativa, a una perspectiva objetiva, por medio del análisis acústico. En particular, se hace una discusión en torno a esta posibilidad, a partir del estudio de la producción de la clase de las fricativas, buscando, también, la profundización de la evaluación fonético-fonológica, enriqueciendo el análisis del sistema fonológico atípico del niño. Al final, se hace una discusión de las ventajas de un abordaje de ese tipo para la terapia fonoaudiológica, así como una discusión en torno a la viabilidad de un análisis de esa naturaleza

PALABRAS CLAVE: Análisis acústico. Trastorno fonológico. Fricativas.

ABSTRACT: This paper analyses the speech data of a 5-year-old child with a phonological disorder in order to combine a phonological analysis, mediated by a generative based representational model, to an objective perspective through acoustic analysis. In particular, a discussion about this possibility is presented, based on the study of the production of the class of the fricatives, also seeking to deepen the phonetic-phonological evaluation, enriching the analysis of the atypical phonological system of the child. In the end, a discussion of the advantages of such an approach to speech therapy is offered, as well as a discussion about the feasibility of such an analysis.

KEYWORDS: Acoustic analysis. Phonological Disorder. Fricatives.

\section{INTRODUÇÃO}

Até a década de 80, o entendimento que se tinha dos desvios fonológicos (DF) era muito incipiente para que se compreendesse e, principalmente, se soubesse como remediar esse quadro. Tanto o era, que a terapia fonoaudiológica para esses casos resumia-se a exercícios de motricidade oral, geralmente em frente a um espelho, pois se acreditava que a criança tinha exclusivamente um problema de articulação dos sons da fala. Além disso, tinha por base a ideia de que o terapeuta deveria ensinar a produção de todos os sons ausentes na fala da criança, o que demonstrava que as técnicas terapêuticas tinham uma concepção comportamentalista e estruturalista de aquisição da linguagem (MOTA, 2001; LAMPRECHT et al., 2004).

A contribuição dada pelos estudos em fonologia gerativa - abordagem que surge para contestar a visão comportamentalista e estruturalista acerca da aquisição da linguagem - é considerada, hoje, como um grande marco para a Fonoaudiologia. Compreender que, mesmo a criança com um desvio severo, apresenta um sistema organizado, com suas regras e restrições, é fundamental na, então, nova concepção de se tratar o DF. Nessas últimas três décadas, com base nessa nova compreensão, novas formas de classificação da severidade do DF surgiram, vários métodos terapêuticos foram testados e modelos de análise foram propostos (LAMPRECHT, 1986; HERNANDORENA, 1988; MOTA, 1990, 1996; KESKE-SOARES, 1996, 2001; LAZZAROTTO, 2005; DUARTE, 2006; LAZZAROTTO-VOLCAO, 2009; GIACCHINI, 2015). Nessa nova concepção, entende-se que a criança tem uma dificuldade em organizar sua gramática de sons. O terapeuta tem a função de auxiliar a criança nesse processo de organização e o 
faz por meio de ações que permitam à criança compreender o valor distintivo dos sons e a empregá-los de modo a produzir os sentidos que deseja. Acredita-se, também, que a criança é criativa e é capaz de generalizar o conhecimento linguístico que adquire nas sessões terapêuticas.

Mais atualmente, em função de maior e mais facilitado acesso à tecnologia e do surgimento de softwares livres, a análise acústica de dados de fala vem sendo utilizada mais amplamente na compreensão dos DF e trazendo novas possibilidades para a terapia fonoaudiológica. Esse tipo de análise permite identificar características como a gradiência fônica. Por exemplo, Cristofolini (2008, 2013) verificou que crianças de diferentes idades e adultos, com fala considerada típica, produzem segmentos plosivos e fricativos com características levemente diferenciadas (gradientes), que não interferem em sua identificação perceptual pelo ouvinte. Várias destas gradiências referem-se à presença/ausência da barra de vozeamento em segmentos plosivos e fricativos, ou seja, foram verificadas interrupções na barra de vozeamento ou sua presença em segmentos não vozeados, em percentuais variáveis. Dentre os casos de gradiência fônica, Rodrigues et al. (2008) ressaltam também a presença dos contrastes fônicos encobertos.

Segundo Berti (2010), contraste fônico encoberto (covert contrast) é a expressão utilizada para descrever o que é categorizado como contrastes fônicos que são imperceptíveis auditivamente, mas detectáveis acústica e/ou articulatoriamente, denotando que a criança usa pistas não robustas e/ou inapropriadas para o segmento em questão ou que ela usa essas pistas em magnitudes não previstas, com valores insuficientes ou exacerbados, que estariam levando à percepção de troca de segmentos. Por exemplo, o estudo Berti e Marino (2011) analisa acusticamente a fala de uma criança com DF, de 6 anos de idade, que neutraliza os contrastes entre as plosivas /t/ e /k/; como resultado aponta que, na verdade, a criança não substitui categoricamente os segmentos, mas sim apresenta contrastes fônicos encobertos, caracterizados pelo uso de um conjunto de pistas fonéticas de forma diferentes das utilizadas por crianças sem alterações na fala. Assim, parece que, mesmo produzindo um alvo de forma diferente da fala típica, algum tipo de distinção fônica a criança realiza, ou seja, verifica-se que crianças com DF produzem sons diferentes para o alvo certo e para o alvo errado, mesmo que para o ouvinte esses sons pareçam iguais.

Esses estudos têm utilizado como suporte teorias que não são de base gerativa, tais como a Fonologia Gestual/Fonologia AcústicoArticulatória, que tomam como primitivo de análise o gesto articulatório que, segundo Albano (2001, p. 52), pode ser definido como "uma oscilação abstrata que especifica constrições no trato vocal e induz os movimentos dos articuladores" - e é, ao mesmo tempo, uma unidade abstrata e concreta.

Desta forma, nesse momento, a questão que se coloca é a seguinte: seria possível aliar uma abordagem acústica a um modelo fonológico representacional? Que tipo de implicações isso pode trazer para a prática fonoaudiológica ou para a teoria linguística? Neste artigo, tem-se como objetivo discutir essa possível abordagem, conciliando análises acústicas e conceitos como gradiência fônica e contrastes encobertos a um modelo representacional gerativista - o Modelo Padrão de Aquisição de Contrastes - PAC (LAZZAROTTO-VOLCÃO, 2009). Esta proposta será discutida a partir de dados de um menino de 5 anos, que apresenta um quadro de DF. Mais especificamente, será analisado o comportamento fonético-fonológico da classe das fricativas, relacionando contrastes encobertos e contrastes fonológicos, com vistas, também, a novas possibilidades terapêuticas.

\section{METODOLOGIA}

Este estudo de caso visa a integrar um modelo fonológico representacional à análise acústica; para tanto, utiliza, como dados de análise, a fala de um menino de cinco anos (chamado aqui de M.), atendido na Clínica Escola de Fonoaudiologia da UFSC, com 
diagnóstico de DF. A fala analisada é resultado de uma avaliação fonológica e de uma gravação de fala espontânea, feitas pelo estagiário-terapeuta, numa mesma sessão, após um período de dois semestres letivos de atendimento no setor.

Os dados da avaliação fonológica foram coletados na sala de terapia, com o auxílio do instrumento Avaliação Fonológica da Criança (YAVAS; MATZENAUER; LAMPRECHT, 1991), transcritos e analisados de acordo com as análises propostas pelo instrumento. Posteriormente, os dados foram interpretados através do modelo fonológico PAC (LAZZAROTTO-VOLCÃO, 2009), descrito na seção 3.1 .

Os dados para a análise acústica foram obtidos através de fala espontânea, a partir de um vídeo gravado também na sala de terapia (ambiente considerado silencioso), por meio de uma filmadora digital (procedimentos de avaliação adotados pelo estagiárioterapeuta). Posteriormente, o arquivo de vídeo foi convertido para áudio (gerando um arquivo no formato wav). A análise acústica foi realizada por meio do software Praat $^{1}$. Durante a análise acústica, primeiramente foi realizada uma inspeção visual geral dos segmentos de fala, buscando características gerais e peculiares na fala de M. e uma primeira caracterização dos segmentos fricativos, objetivo deste estudo. Em seguida, os dados foram segmentados e etiquetados, contando com 4 tiers: no primeiro, foram destacados os enunciados de M. (separando-os da fala do estagiário-terapeuta); no segundo, segmentou-se as palavras que continham segmentos fricativos, no terceiro, os segmentos fricativos, ou melhor, a pausa destinada à marcação do tempo fonológico da fricativa (uma vez que M. aparentemente não produz segmentos fricativos) e, no quarto, dados da duração (em ms) destes segmentos/pausas e observações qualitativas. Posteriormente, os valores de duração da palavra e dos segmentos fricativos foram extraídos manualmente. Para a tabulação dos dados, foram considerados o segmento fricativo propriamente dito, seus respectivos pontos de articulação e vozeamento. Como critérios de análise, foram contempladas a duração relativa da pausa/tempo fonológico destinado à fricativa em questão em relação à palavra que a contém; a duração dos segmentos fricativos em relação ao ponto articulatório e a diferença entre a duração dos segmentos fricativos não vozeados e fricativos vozeados. Ainda, num complemento à análise das fricativas, foram selecionadas alguns segmentos africados, que também foram analisados seguindo os critérios destinados às fricativas. Num segundo momento da análise acústica, os dados de M. foram comparados com um grupo controle (CRISTOFOLINI, 2013) ${ }^{2}$, também formado por crianças de 6 anos, na mesma faixa etária de M.

Como é sabido que a taxa de elocução do falante influencia diretamente na duração absoluta dos segmentos de fala, optou-se em realizar as análises temporais somente a partir de dados relativos, ou seja, o percentual que o segmento/pausa ocupa em relação à palavra, tanto nos dados de M. quanto nos dados do grupo controle.

Finalmente, destaca-se que esta pesquisa é integrante do Projeto de Pesquisa "O detalhe acústico: uma análise acústica exploratória dos segmentos de fala”, aprovado pelo Comitê de Ética em Pesquisa com Seres Humanos da UFSC, sob o n. 2057.

\section{ANÁLISE DOS DADOS}

\subsection{ANÁLISE FONOLÓGICA}

3.1.1 O Modelo Padrão de Aquisição de Contrastes (PAC)

${ }^{1}$ PRAAT: doing phonetics by computer. Software de análise de fala, versão 5.2.22, disponível livremente a partir do site www.praat.org; copyright (C) 1992-2011 by Paul Boersma and David Weenink.

${ }^{2}$ Os dados do grupo controle advêm de parte do estudo (CRISTOFOLINI, 2013), feito para a tese "Gradiência na fala infantil: caracterização acústica de segmentos plosivos e fricativos e evidências de um período de 'refinamento articulatório"'. 
O modelo desenvolvido em Lazzarotto-Volcão (2009) foi proposto para avaliar a aquisição fonológica em crianças falantes do PB e identificar casos de DF. Essa proposta incorpora os princípios fonológicos propostos por Clements (2009 [2005]), os quais estão descritos a seguir, de forma resumida:

a) Feature Bounding (Limitação de Traços) - este princípio refere-se ao poder que os traços possuem de aumentar o número de categorias potencialmente contrastivas em um sistema.

b) Feature Economy (Economia de Traços) - de acordo com este princípio, os traços tendem a ser combinados maximamente.

c) Marked Feature Avoidance (Evitação de Traços Marcados) - este princípio afirma que certos valores de traços tendem a ser evitados pelas línguas.

d) Robustness (Robustez) - este princípio diz respeito ao fato de certos contrastes, relativos a traços mais robustos, apresentarem a tendência de serem mais frequentes se comparados a contrastes relativos a traços menos robustos.

e) Phonological Enhancement (Reforço Fonológico) - por fim, este princípio refere-se ao fato de valores marcados de traços poderem ser introduzidos em um sistema para reforçar contrastes perceptuais fracos.

Além de embasar seu modelo nesses princípios, a autora faz algumas adaptações necessárias, por conta das particularidades do PB e do processo de aquisição dessa língua, como língua materna. Os dados empíricos da aquisição tomados como parâmetro para essas adaptações estão em Lamprecht et al. (2004).

O PAC permite analisar o inventário de sons de uma criança durante a aquisição e identificar casos de DF, bem como avaliar a gravidade desse desvio. Esse modelo analisa os segmentos (e, portanto, os contrastes) presentes no sistema e, também, como a criança ocupa os espaços fonológicos ausentes - fato não observado em outras propostas de análise da fonologia infantil.

São previstas quatro grandes etapas do processo de aquisição, em que os contrastes vão emergindo a partir da aquisição de novos traços pela criança, ou à medida que novas coocorrências vão sendo estabelecidas. Na figura 1 tem-se uma visão geral do modelo, em que cada etapa está representada por uma tonalidade específica. 

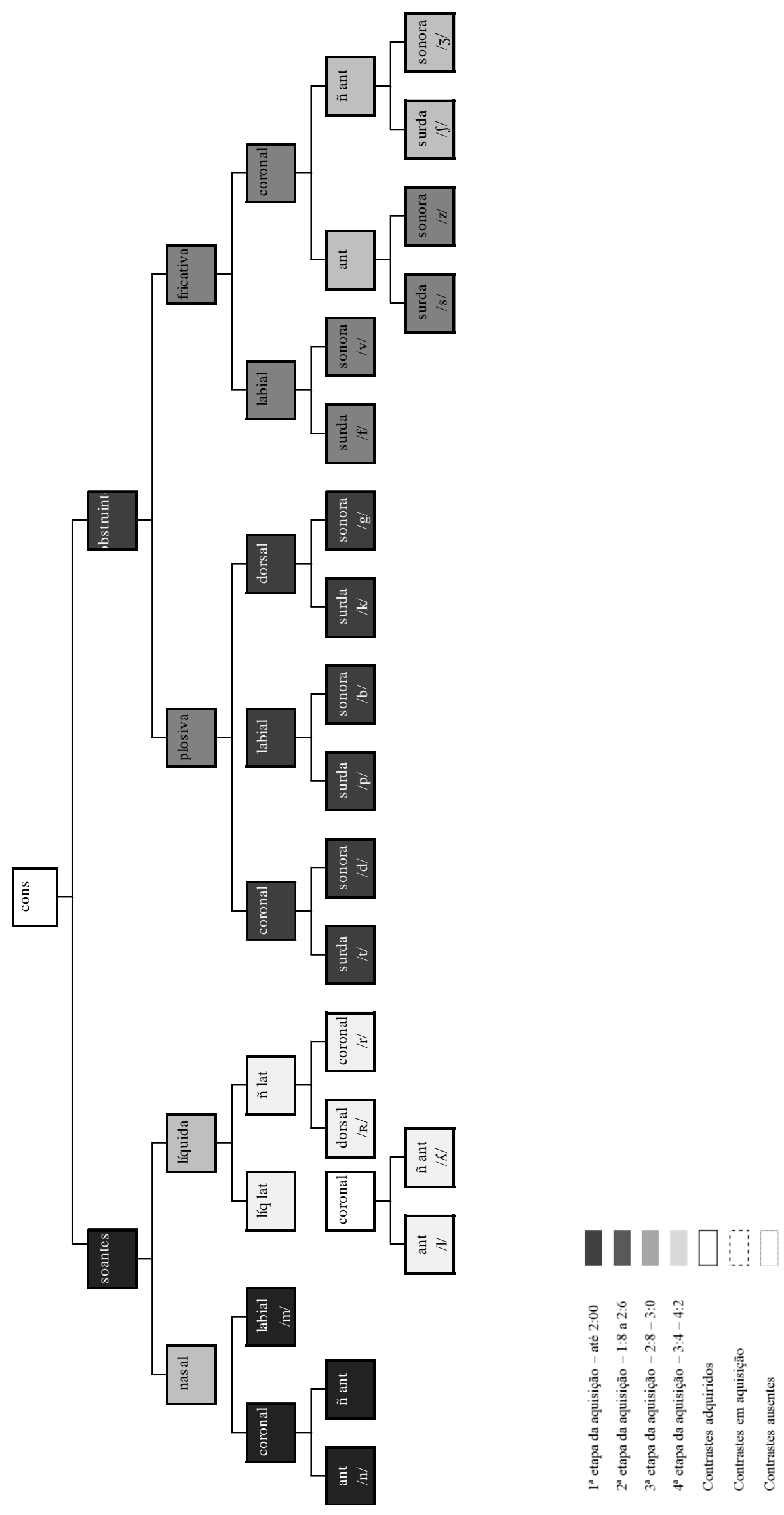

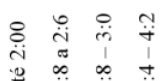

का

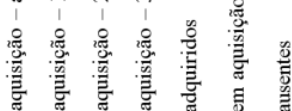

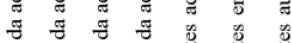

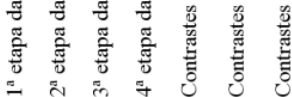

Figura 1: Etapas da aquisição do PB, segundo o Modelo PAC.

Fonte: Lazzarotto-Volcão (2009). 
Para mais bem compreender as quatro etapas propostas pelo PAC, apresenta-se, a seguir, o Quadro 1, em que constam os traços marcados que surgem em cada etapa, as coocorrências que se estabelecem e os contrastes que emergem a partir disso. É importante destacar nesse quadro que, a partir da $4^{\mathrm{a}}$ etapa, não há a aquisição de traços novos. Indo além, podemos ver que já na primeira etapa do processo de aquisição, quase todos os traços (5 de 7) já emergem no sistema fonológico da criança. Esse fato evidencia que a complexidade do sistema vai-se configurando através das coocorrências que surgem a partir dos traços adquiridos. Essas coocorrências é que fazem com que os vários contrastes surjam no sistema (HERNANDORENA, 1990; LAZZAROTTO-VOLCÃO E MATZENAUER, 2008; LAZZAROTTO-VOLCÃO, 2009).

\begin{tabular}{|c|c|c|c|}
\hline $\begin{array}{l}\text { Etapas de } \\
\text { aquisição } \\
\text { do PAC }\end{array}$ & $\begin{array}{l}\text { Traços } \\
\text { adquiridos }\end{array}$ & Coocorrências formadas & $\begin{array}{l}\text { Contrastes estabelecidos a partir das } \\
\text { coocorrências }\end{array}$ \\
\hline 1 & $\begin{array}{l}\text { [+soante }] \\
{[\text { labial }]} \\
{[\text { dorsal }]} \\
{[\text {-anterior }]} \\
{[+ \text { voz }]} \\
\\
\end{array}$ & $\begin{array}{l}\text { [+consonantal, }+ \text { soante }] \\
{[\text {-soante, labial }]} \\
{[\text {-soante, dorsal }]} \\
{[+ \text { soante, labial }]} \\
{[+ \text { soante, coronal, -anterior }]} \\
{[\text {-soante, coronal, +voz }]} \\
{[\text {-soante, labial, +voz }]} \\
{[\text {-soante, dorsal, +voz }]} \\
\text { Total da etapa: } 8\end{array}$ & $\begin{array}{l}\text { Soantes versus obstruintes } \\
\text { Plosivas coronais versus labiais } \\
\text { Plosivas coronais versus dorsais } \\
\text { Plosivas labiais versus dorsais } \\
\text { Nasais coronais versus labial } \\
\text { Nasais coronais anterior versus não- } \\
\text { anterior } \\
\text { Plosivas coronais surda versus sonora } \\
\text { Plosivas labiais surda versus sonora } \\
\text { Plosivas dorsais surda versus sonora } \\
\text { Total da etapa: } 9\end{array}$ \\
\hline 2 & $\begin{array}{l}\text { [+contínuo] } \\
\text { Total da etapa: } 1 \\
\text { Total da gramática: } 6\end{array}$ & $\begin{array}{l}{[\text {-soante, }+ \text { contínuo }]} \\
{[+ \text { continuo, labial }]} \\
{[+ \text { contínuo, coronal, }+ \text { voz }]} \\
{[+ \text { contínuo, labial, }+ \text { voz }]}\end{array}$ & $\begin{array}{l}\text { Plosivas versus fricativas } \\
\text { Fricativas coronais versus labiais } \\
\text { Fricativas coronais surda versus sonoras } \\
\text { Fricativas labiais surda versus sonora } \\
\text { Total da etapa: } 4 \\
\text { Total da gramática: } 13\end{array}$ \\
\hline 3 & $\begin{array}{l}\text { [+aproximante] } \\
\\
\text { Total da etapa: } 1 \\
\text { Total da gramática: } 7\end{array}$ & 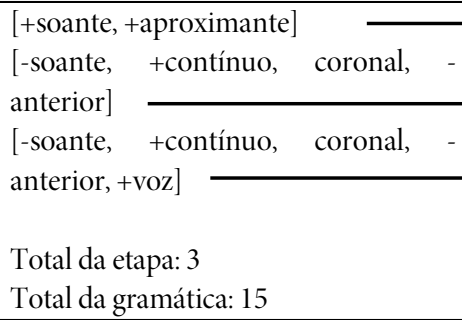 & $\begin{array}{l}\text { Nasais versus líquidas } \\
\text { Fricativas coronais anteriores versus não- } \\
\text { anteriores } \\
\text { Fricativas coronais não-anteriores surdas } \\
\text { versus sonoras } \\
\text { Total da etapa: } 3 \\
\text { Total da gramática: } 16\end{array}$ \\
\hline 4 & 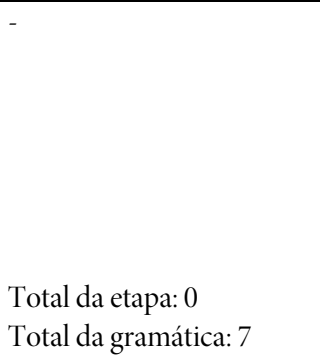 & $\begin{array}{l}\text { [+aproximante, +contínuo] } \\
\text { [+aproximante, -contínuo, coronal, - } \\
\text { anterior] } \\
\text { [+aproximante, +contínuo, dorsal] } \\
\text { Total da etapa: } 3 \\
\text { Total da gramática: } 18\end{array}$ & $\begin{array}{l}\text { Líquidas laterais versus não-laterais } \\
\text { Líquidas laterais anterior versus não- } \\
\text { anterior } \\
\text { Líquidas não-laterais coronal versus } \\
\text { dorsal } \\
\text { Total da etapa: } 3 \\
\text { Total da gramática: } 19\end{array}$ \\
\hline
\end{tabular}

Quadro 1: Contrastes da fonologia do PB e as fases de aquisição

Fonte: Lazzarotto-Volcão (2009) 
O PAC tem sido utilizado em trabalhos que buscam compreender não somente a aquisição fonológica atípica (GIACCHINI, 2015), mas, também, a aquisição típica do PB (MARQUES, 2016; MARQUES; LAZZAROTTO-VOLCÃO, 2018) e de outras línguas, como é o caso do trabalho de Viraque (2014), que analisou a aquisição do espanhol uruguaio, e de Amorin (2014), LazzarottoVolcão (2016) e Reis (2018), que analisaram a aquisição do português europeu (PE).

Na próxima seção, será descrito o sistema fonológico do caso em tela.

\subsubsection{O sistema fonológico de M.}

Conforme mencionado, os dados aqui analisados referem-se a um momento do período de aquisição de M., cinco anos, que está em atendimento fonoaudiológico. O sistema consonantal dessa criança é formado por plosivas e nasais. As plosivas encontram-se todas adquiridas, enquanto que da classe das nasais, apenas a labial /m/. A partir de uma análise de oitiva, percebe-se que o espaço das fricativas e das nasais não adquiridas não é preenchido por nenhum segmento. Já o espaço das líquidas, é preenchido por outras líquidas ([r] e [l]), em alternância com o zero fonético. Em relação às estruturas silábicas, M. ainda não adquiriu estruturas do tipo CVC e CCV, produzindo apenas sílabas do tipo CV e V. No Quadro 2, tem-se o inventário fonológico do menino.
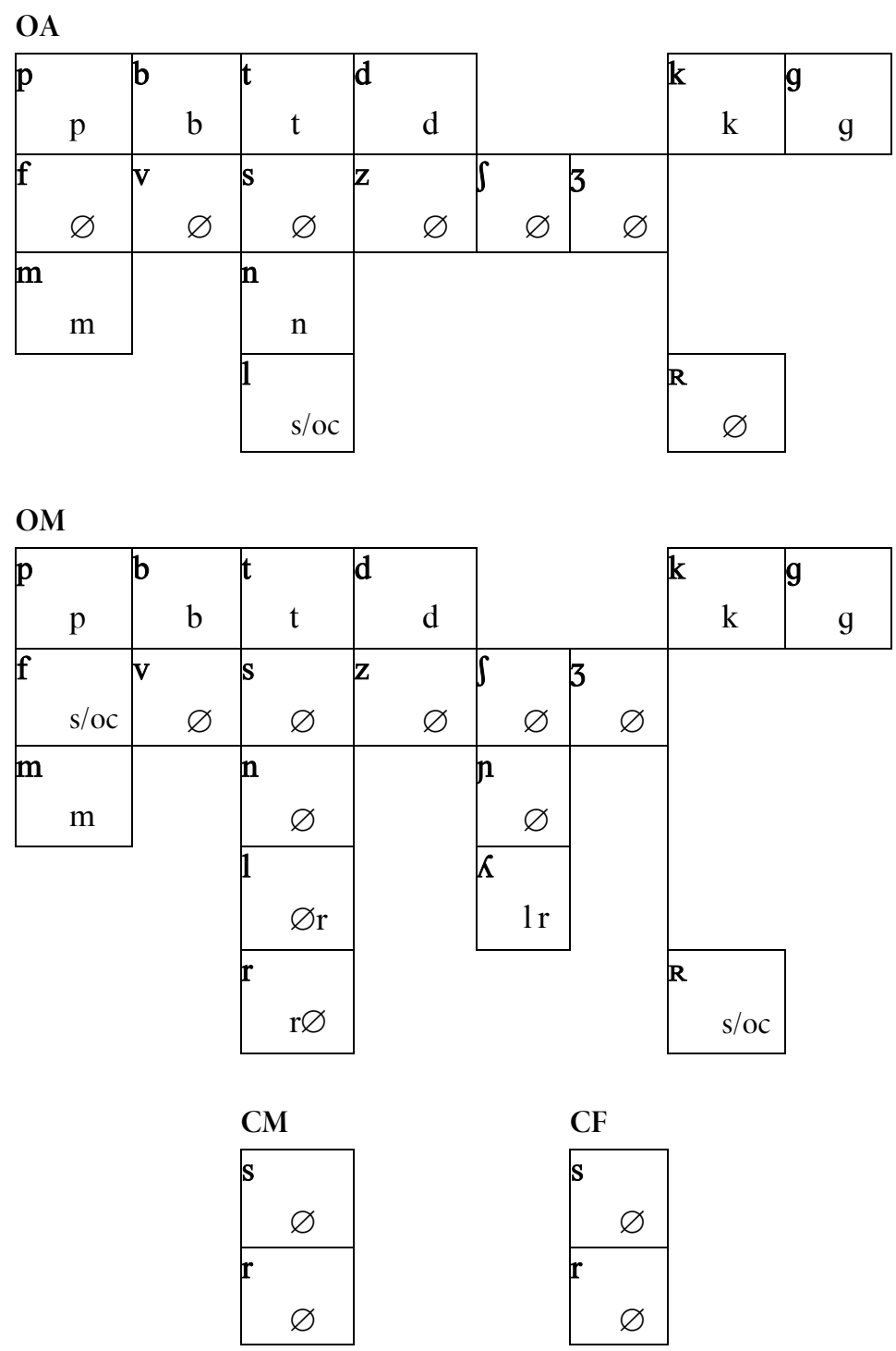

Quadro 2: inventário fonológico de $\mathrm{M}$

Fonte: própria (2019) 
Em relação aos contrates presentes na gramática de M., a análise mediada pelo PAC evidencia que apenas os contrastes da primeira etapa e um contraste da terceira estão estabelecidos, a saber: soantes x não soantes; labial x coronal (no contexto das nasais); dorsal $\mathrm{x}$ labial x coronal (no contexto das plosivas); vozeado x não vozeado (no contexto das plosivas) - todos da primeira etapa - e nasal x líquida, da terceira. Na Figura 2 tem-se o desenho do PAC para o sistema de M.

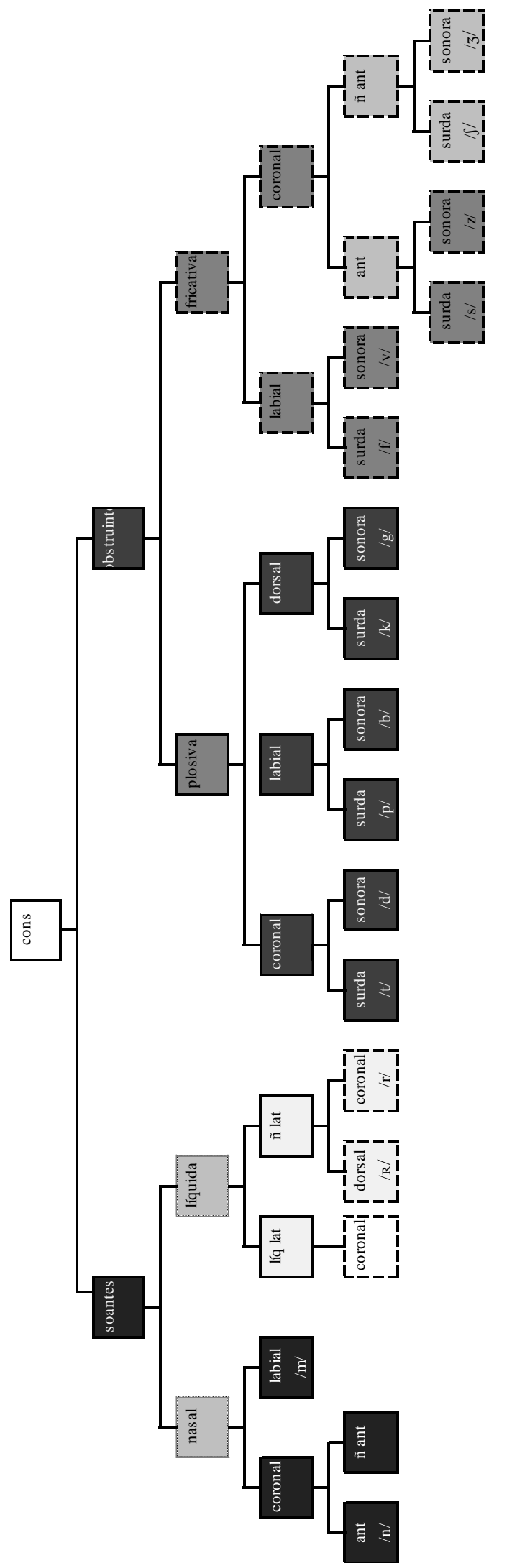

Figura 2: sistema fonológico de M. por meio do PAC

Fonte: própria (2019) 
Do ponto de vista fonológico, então, pode-se dizer que M. ainda não iniciou a construção dos segmentos fricativos, uma vez que nada produz em seu espaço fonológico. É nessa característica da fala do menino que a análise acústica vai se debruçar.

\subsection{ANÁLISE ACÚSTICA - AS FRICATIVAS}

Como exposto na seção sobre a análise fonológica dos dados de M., a partir de análises de oitiva (tanto durante a fala corriqueira quanto numa análise perceptivo-auditiva mais apurada, no início da análise acústica) observa-se que, na fala de M., há uma "pausa" no espaço das fricativas, classe ainda não adquirida. Assim, o primeiro objetivo da análise acústica foi precisar se realmente não haveria um segmento neste espaço (que não estaria sendo percebido de oitiva), partes de um segmento ou mesmo um contraste encoberto. Assim, todas as fricativas em onset silábico pertencentes aos dados foram analisadas acusticamente, tanto as em onset absoluto quanto em onset medial, preferencialmente em sílabas do tipo CV, estrutura silábica já adquirida por M..

Assim, nesta primeira análise, observa-se que, realmente, M. não realiza nenhum segmento no espaço fonológico destinado às fricativas $^{3}$, como pode ser observado nos exemplos ilustrados nas Figuras 3 e 4.

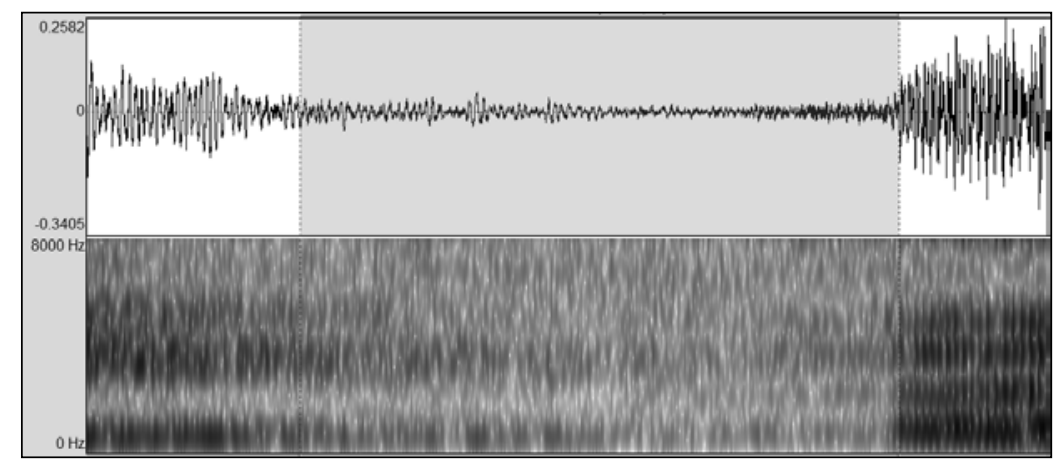

Figura 3: Forma de onda e espectrograma de exemplos do espaço fonológico (pausa) que marca a região do segmento fricativo não vozeado [f], na palavra "rifa"; visível ['i $\varnothing \mathbf{e}]$.

Fonte: própria (2019)

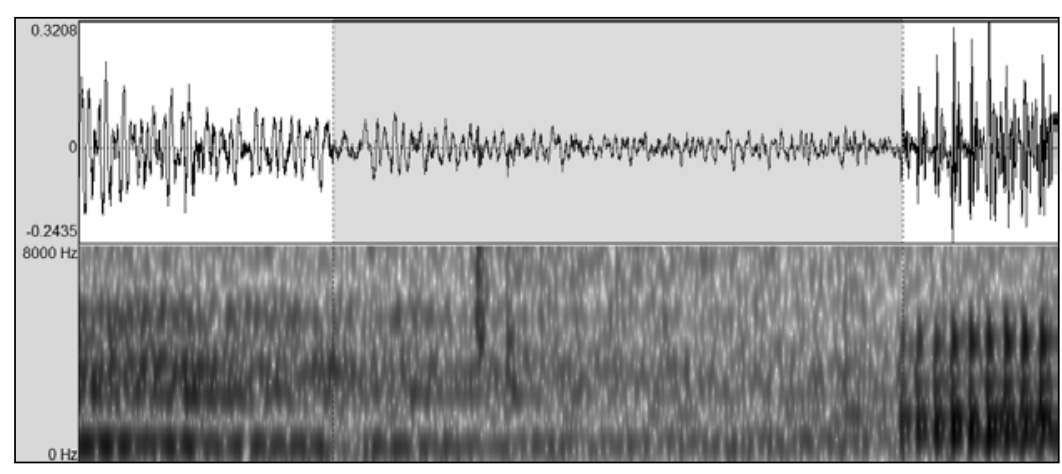

Figura 4: Forma de onda e espectrograma de exemplos do espaço fonológico (pausa) que marca a região do segmento fricativo não vozeado [v], na palavra "leva(r)"; visível [e'Øa].

Fonte: própria (2019)

\footnotetext{
${ }^{3}$ Observa-se a presença de uma pequena oscilação na forma de onda, que poderia ser indício da presença de uma fricativa, mas observam-se estas mesmas oscilações, constantes, com as mesmas características de frequências e com poucas variações de intensidade nas pausas da gravação e nos momentos de silêncio. Assim, acreditase que estas oscilações estejam mais relacionadas à presença de ruídos ambientais (apesar da gravação ter sido efetuada em ambiente silencioso) e/ou do equipamento utilizado para a gravação ou mesmo da conversão do arquivo de vídeo para áudio do que para a presença de uma fricativa propriamente dita.
} 
Sabe-se que uma das características acústicas dos segmentos fricativos é a fricção, que resulta na presença de energia em altas frequências. Segundo Russo e Behlau (1993), a faixa de frequências das fricativas é ampla, variando de 1200 a 8000 Hz: [s] e [z] são os mais agudos (entre 4500 e $8000 \mathrm{~Hz}$ ) e [S] e [3] os mais graves (entre 2500 e $6000 \mathrm{~Hz}$ ). Esta presença de energia nas altas frequências não foi observada no espaço destinado às fricativas da fala de M. (como pode ser observado nas figuras 4 e 5), exceto quando ele produz a fricativa isolada, como ilustrado na Figura 5.

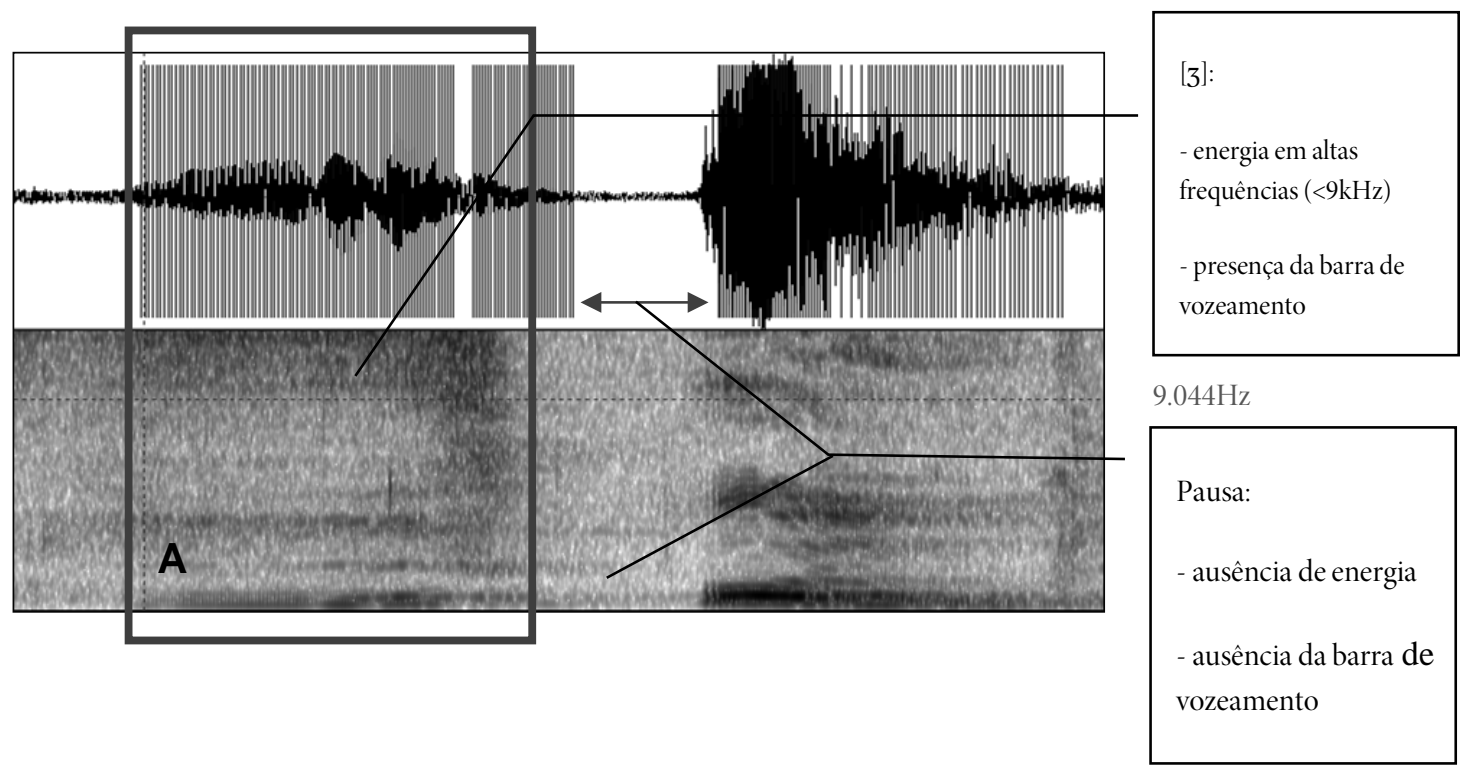

Figura 5: Forma de onda e espectrograma da palavra “junto”, com destaque, no quadro A, para a produção isolada de [3].

Fonte: própria (2019)

Como já comentado, no momento da coleta, M. já estava em atendimento fonoaudiológico há dois semestres letivos na Clínica Escola de Fonoaudiologia da UFSC. Durante esses atendimentos, a estratégia de alongamento da fricativa foi bastante utilizada pelo estagiário-terapeuta. Assim, observa-se que M. produz "corretamente" o segmento de forma isolada (quadro A da Figura 5), mas realiza uma pausa (destacada, também na Figura 6, pela seta dupla e percebida também pela análise de oitiva), com interrupção da presença de energia em altas frequências, e depois enuncia o restante da palavra. Destaca-se que, na pausa, há também a interrupção da barra de vozeamento. O mesmo ocorre para as demais fricativas: isoladamente, são produzidas de forma adequada.

Além disso, ainda durante as análises de oitiva e também durante a análise acústica, notou-se que os segmentos africados produzidos por M. são percebidos corretamente e sua configuração acústica também é típica. Por isso, optou-se em incluir os dados das africadas nas análises acústicas mais detalhadas, a fim de obter um maior detalhamento acústico de sua produção.

Um segundo objetivo da análise acústica, então, foi verificar se o tempo de pausa feito por M. seria condizente ao tempo que as fricativas ocupam em dados de fala de crianças com fala típica, sem queixas e/ou alterações de fala, linguagem e/ou audição. No gráfico apresentado na Figura 6 têm-se então os dados da duração relativa do tempo de pausa dos fricativos de M., comparados aos do grupo controle. 


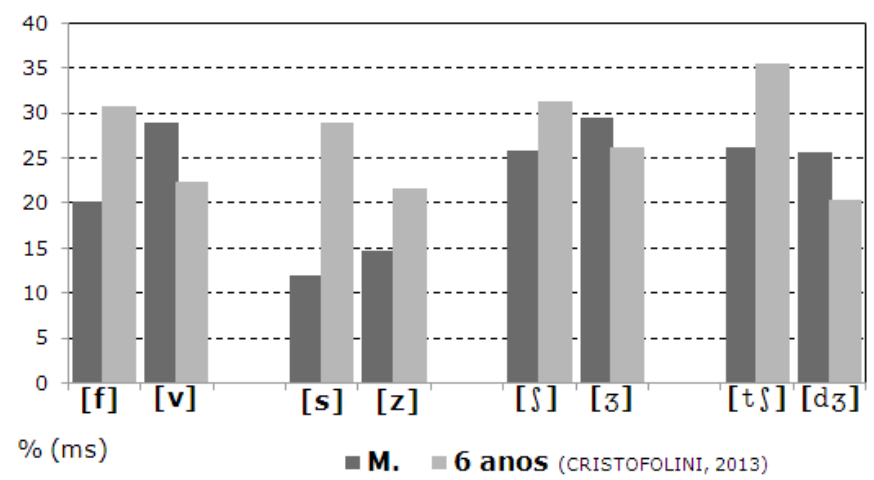

Figura 6: Comparativo da duração relativa dos segmentos fricativos

Fonte: própria (2019)

Observa-se que M. faz a marcação do tempo fonológico das fricativas de uma forma diferente da feita pelas crianças do grupo controle: os tempos de pausa relativos aos segmentos fricativos não vozeados de $\mathrm{M}$. são sempre relativamente menores que os segmentos fricativos do grupo controle enquanto que os vozeados são maiores, exceto para [z]. O mesmo ocorre para as africadas (que M. produz de forma típica), com [t $\mathrm{t}]$ apresentando uma duração relativa menor e [dz], maior.

Destas observações decorre uma primeira revisão da avaliação fonológica. Um dos critérios, embora não o único ${ }^{4}$, para a distinção entre segmentos fricativos vozeados e não vozeados é a duração do segmento (RUSSO;BEHLAU, 1993; BERTI, 2006). Observa-se que M. faz uma "distinção" entre a duração relativa do tempo de pausa relativo aos segmentos fricativos vozeados e não vozeados, embora essa sua "distinção" não seja a mesma feita pelas crianças do grupo controle, ou seja, este poderia ser um dos contrastes encobertos presentes na fala de M..

Ainda em relação à duração/distinção de sonoridade, sabe-se que os segmentos fricativos não vozeados têm maior duração do que os fricativos vozeados, pois a produção de um fricativo vozeado demanda também que haja um aumento no tamanho da glote para que seja possível originar um fluxo de ar suficiente para gerar um ruído fricativo e vozeado (HEINZ; STEVENS, 1997). Para Russo e Behlau (1993), a diferença entre os segmentos homorgânicos deve ser em torno de 40ms; para Haupt (2007) o segmento vozeado deve corresponder a 50\% da duração do não vozeado. Em pesquisas com informantes infantis, Cristofolini (2013) verificou que a diferença se mantém também para crianças, mas com valores percentuais maiores, variando entre 66 e $87 \%$, ou seja, em crianças, a relação da duração entre segmentos fricativos não vozeados e vozeados é menor. O mesmo acontece com M., para os fricativos dentais e palatais, mas não para os fricativos alveolares. A diferença entre [s] e [z], para M., é de 117\%, ou seja, em sua fala, o tempo de pausa relativo ao segmento vozeado é maior do que o não vozeado, contrariando a tendência apontada anteriormente.

Além disso, há uma correção positiva entre o ponto articulatório e a duração dos segmentos fricativos, havendo o aumento da duração do segmento à medida que seu ponto articulatório se posterioriza. Em informantes infantis de 6 anos de idade, esta relação foi observada apenas em segmentos fricativos vozeados; em segmentos não vozeados, foi observado exatamente o contrário: segmentos com ponto de articulação mais posteriores (palatais) são mais breves do que os anteriores (lábio-dentais) (CRISTOFOLINI, 2013). Exatamente esta mesma tendência foi observada nos dados dos tempos de pausas relativas às fricativas de M., conforme pode ser observado na Figura 7.

\footnotetext{
${ }^{4}$ Berti (2006) aponta três parâmetros importantes no estudo dos fricativos: a duração e a amplitude do ruído e a região no espectro de maior concentração de energia.
} 


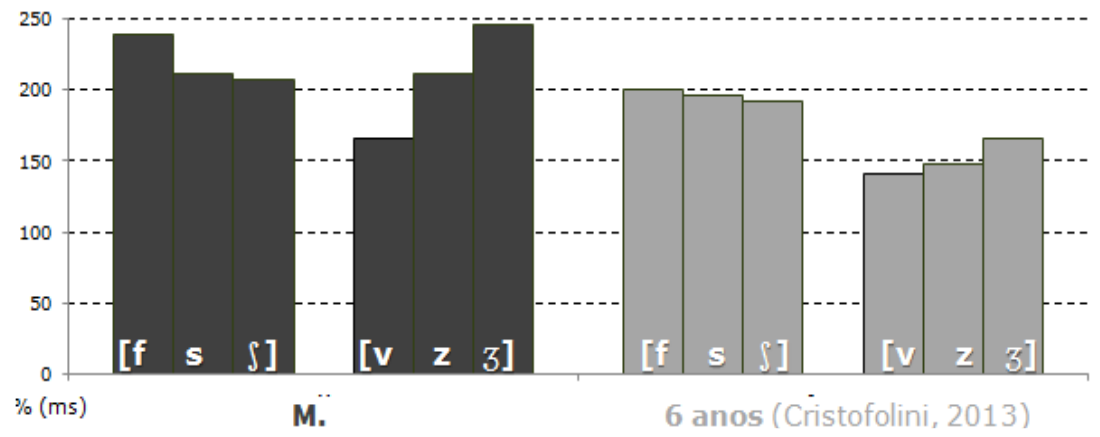

Figura 7: Comparativo da duração relativa dos segmentos fricativos em relação ao ponto articulatório

Fonte: própria (2019)

Daí decorre a segunda implicação para a análise fonológica de M.; parece que a pausa que ele faz no tempo fonológico da fricativa segue a mesma tendência de duração em relação ao ponto articulatório das crianças de 6 anos de idade do grupo controle, ou seja, este poderia ser mais uma evidência da presença de contrastes encobertos presentes nos segmentos fricativos na fala de $\mathrm{M}$.

Assim, a análise acústica permitiu verificar que, neste caso em particular, não há a evidências de dados acústicos que possam ser característicos da presença propriamente dita de segmentos fricativos, mas que M. marca o tempo fonético-fonológico destes segmentos de forma "adequada" em relação ao ponto articulatório e de forma inversa em relação à sonoridade. Com isso, contrariamente ao apontado ao fim da avaliação fonológica, podemos dizer que M. já deu início à construção interna do segmento, mesmo que ainda sem uma manifestação fonética perceptível.

\section{CONSIDERAÇÕES FINAIS E IMPLICAÇÕES PARA AVALIAÇÃO E TERAPIA FONOAUDIOLÓGICAS}

A partir da análise de oitiva, numa avaliação fonológica clínica "clássica”, chega-se a conclusão que M. não produz as fricativas (zero fonético), ou seja, ainda não adquiriu a classe das fricativas. Com a inserção da avaliação acústica, observou-se que, além de M. marcar o tempo fonética/fonológico da classe das fricativas, demonstrando conhecimento fonológico, M. também apresenta características que podem ser consideradas contrastes encobertos, embora bastante rudimentares: a marcação do tempo fonológico em relação ao ponto e ao vozeamento (este, de forma inversa às crianças do grupo controle). Mas, mesmo sendo contrastes bastante básicos, estes dados mostram que M. já adquiriu algumas características dos segmentos fricativos, embora ainda não mostre sua realização fonética. Não se tem dados gravados em áudio/vídeo do início do processo terapêutico de M. para distinguir se ele sempre fez esta marcação ou se foi algo adquirido com a terapia, mas, mesmo assim, já permite uma mudança no olhar sobre sua avaliação.

Com isso, conclui-se também que ambas as formas de análise podem ser complementares: a análise acústica permite um maior entendimento da produção de M., que não seriam percebidas em uma análise apenas de oitiva, permitindo uma melhor análise do sistema fonológico em aquisição.

Essa complementaridade enriquece a análise do sistema fonológico atípico e permite um planejamento terapêutico com maiores possibilidades de sucesso, levando em conta também características individuais, ou seja, "encaixa-se o modelo ao indivíduo" e não "o indivíduo ao modelo". Por exemplo, retomando-se o caso dos segmentos africados, produzidos de forma típica por M., pode-se pensar em uma estratégia diferenciada de terapia. De acordo com o modelo do PAC, propõe-se que o alvo da terapia seja trabalhar com a fricativa mais marcada do sistema (/Z/), para que as outras surjam por generalização. Mas, uma vez que M. produz adequadamente as africadas $\left(\left[\mathrm{t} \int\right]\right.$ e $\left.\left[\mathrm{d}_{3}\right]\right)$, poder-se-ia propor, como estratégia terapêutica, produzir, inicialmente, os alvos com fricativas como africadas, como, por exemplo, [dz]irafa e $\left[\mathrm{t} \int\right]$ ícara e, gradativamente, robustecer a porção fricativa do segmento 
buscando a generalização para outros contextos vocálicos (inclusive, dependendo de como a estratégia fosse utilizada por M., usando contextos não usuais das africadas, como no exemplo ilustrado na Figura 6, "[dz] unto" 5 ).

Finalmente, defende-se ainda que essa proposta não fere a concepção de crença na existência do nível abstrato da fonologia e, consequentemente, na existência de traços distintivos na estrutura interna dos segmentos. Concebe-se também que é possível aliar alguns conceitos das teorias mais dinâmicas, como a gradiência e o contraste encoberto, mas, ao mesmo tempo, utilizar uma análise representacional que permite "delimitar" os segmentos, ou melhor, o caráter distintivo que eles assumem na língua. Supõe-se esta conciliação pensando, por exemplo, também na representação categórica do fonema que a criança precisa ter durante o processo de alfabetização, principalmente nos momentos de associação grafema/fonema, embora haja gradiência na sua produção articulatória.

\section{REFERÊNCIAS}

AMORIN, C. Padrão de aquisição de contrastes do PE: A interação entre traços, segmentos e sílabas. 2014. Tese (Doutorado) Universidade do Porto, Porto, 2014.

BERTI, L. C. Aquisição incompleta do contraste entre /s/ e / / / em crianças falantes do português brasileiro. 2006. Tese (Doutorado) LAFAPE, IEL, Universidade de Campinas, Campinas, 2006.

BERTI, L. C.; MARINO, V. C. de C. Contraste fônico encoberto entre /t/ e /k/: um estudo de caso de normalidade e de transtorno fonológico. Revista CEFAC, São Paulo, v. 113, n.2, p.866-875, 2011.

CRISTOFOLINI, C. Erros ortográficos: um estudo a partir de análises acústicas. 2008. Dissertação (Mestrado) - Programa de PósGraduação em Linguística, Universidade Federal de Santa Catarina, Florianópolis, 2008.

CRISTOFOLINI, C. Gradiência na fala infantil: caracterização acústica de segmentos plosivos e fricativos e evidências de um período de "refinamento articulatório". 2013. Tese (Doutorado) - Programa de Pós-Graduação em Linguística, Universidade Federal de Santa Catarina, Florianópolis, 2013.

DUARTE, S. Relações de distância e de complexidade entre traços distintivos na generalização em terapia de desvios fonológicos. 2006. Dissertação (Mestrado) - Universidade Católica de Pelotas, Pelotas, 2006.

GIACCHINI, V. Proposta de modelo padrão de aquisição de contrastes e estruturas (PAC-E) para avaliação dos desvios fonológicos. 2015. Tese (Doutorado) - Universidade Federal de Santa Maria, Santa Maria, 2015.

HAUPT, C. Os fricativos [s], [z], [J] e [3] do português brasileiro. Estudos Linguísticos, ed. 26, n.1, p. 37-46, jan./abr. 2007.

HEINZ, J. M.; STEVENS, K, N. On the properties of voiceless fricative consonants. In: The Journal of the Acoustical Society of America, v. 33, n. 5, p. 589-596, maio1961.

HERNANDORENA, C. L. Uma proposta de análise de desvios fonológicos através de traços distintivos. 1988. Dissertação (Mestrado) - Pontifícia Universidade Católica do Rio Grande do Sul, Porto Alegre, 1988.

\footnotetext{
${ }^{5}$ Sabe-se que as africadas, no português brasileiro, só ocorrem diante de vogais altas anteriores; porém, como M. produz "adequadamente" as africadas neste contexto, como em [dz]ia e ves $\left[\mathrm{t} \int\right]$ ido, por exemplo, acredita-se que as africadas possam ser usadas, como estratégias terapêuticas, em outros contextos também.
} 
KESKE-SOARES, M. Aplicação de um modelo de terapia fonológica para crianças com desvios fonológicos evolutivos: a hierarquia implicacional dos traços distintivos. 1996. Dissertação (Mestrado) - Pontifícia Universidade Católica do Rio Grande do Sul, Porto Alegre, 1996.

KESKE-SOARES, M. Terapia fonoaudiológica fundamentada na hierarquia implicacional dos traços distintivos aplicada em crianças com desvios fonológicos. 2001. Tese (Doutorado) - Pontifícia Universidade Católica do Rio Grande do Sul, Porto Alegre, 2001.

LAMPRECHT, R. R. Os processos nos desvios fonológicos evolutivos: estudo sobre quatro crianças. 1986. Dissertação (Mestrado) Pontifícia Universidade Católica do Rio Grande do Sul, Porto Alegre, 1986.

LAMPRECHT, R. R. et al. Aquisição fonológica do português. Porto Alegre: Artmed; 2004.

LAZZAROTTO, C. Avaliação e planejamento fonoterapêutico para casos de Desvio Fonológico com base na Teoria da Otimidade. 2005. Dissertação (Mestrado) -Universidade Católica de Pelotas, Pelotas, 2005.

LAZZAROTTO-VOLCÃO, C. ; MATZENAUER, C. L.B. A severidade do desvio fonológico com base em traços. Letras de Hoje, Porto Alegre, v .43, n.3, p.47-53, 2008.

LaZZArotto-VOlCÃO, C. Modelo Padrão de Aquisição de Contrastes. Tese de Doutorado. Universidade Católica de Pelotas, 2009.

LAZZAROTTO-VOLCÃO, C. Aspectos da aquisição fonológica com desvios em crianças brasileiras e portuguesas. [Apresentação de comunicação oral. Lisboa: Centro de Linguística, Universidade de Lisboa, 2016].

MARQUES, T. F. Aquisição fonológica do português brasileiro em gêmeos dizigóticos. 2016. Dissertação (Mestrado) - Programa de Pós-Graduação em Linguística, Universidade Federal de Santa Catarina, Florianópolis, 2016.

MARQUES, T. F; LAZZAROTTO-VOLCÃO, C. Aquisição fonológica típica à luz do modelo padrão de aquisição de contrastes. In: LAZZAROTTO-VOLCÃO, C; FREITAS, M. J. Estudos em Fonética e Fonologia: uma homenagem a Carmen Matzenauer. Curitiba: CRV, 2018. p. 248-86.

MOTA, H. B. Uma abordagem terapêutica baseada nos processos fonológicos no tratamento de crianças com desvios fonológicos. 1990. Dissertação (Mestrado) - Pontifícia Universidade Católica do Rio Grande do Sul, Porto Alegre, 1990.

MOTA, H. B. Aquisição segmental do Português: um modelo implicacional de complexidade de traços. 1996. Tese (Doutorado) Pontifícia Universidade Católica do Rio Grande do Sul, Porto Alegre, 1996.

MOTA, H. B. Terapia fonoaudiológica para os desvios fonológicos. Rio de Janeiro: Revinter, 2001. 
RODRIGUES, L. L. et al. Acertos gradientes nos chamados erros de pronúncia. Revista Letras, n. 36, p. 85-112. jan./jun. 2008

REIS, T. B. dos. A avaliação fonológica na perturbação dos sons da fala - modelo padrão de aquisição de contrastes: estudo de caso. 2018. Dissertação (Mestrado) - Universidade de Lisboa, Lisboa, 2018.

RUSSO, I.; BEHLAU, M. Percepção da fala: análise acústica. São Paulo: Lovise, 1993. 57p.

VIRAQUÉ, B. R. A construção da fonologia por crianças falantes nativas de espanhol: a aquisição do sistema consonantal. 2014. Dissertação (Mestrado) Universidade Católica de Pelotas, Pelotas, 2014.

YAVAS, M.; MATZENAUER-HERNANDORENA, C. L.; LAMPRECHT, R. R. Avaliação fonológica da criança. Porto Alegre: Artes Médicas, 1991.

\section{()(1) $\Theta \Theta$}

